Western University

Scholarship@Western

Undergraduate Honors Posters

Psychology Department

Winter 4-30-2014

\title{
Ideal Mate Preferences and Relationship Initiation
}

Kristi A. Chin

kchin25@uwo.ca

Follow this and additional works at: https://ir.lib.uwo.ca/psychd_posters

Citation of this paper:

Chin, Kristi A., "Ideal Mate Preferences and Relationship Initiation" (2014). Undergraduate Honors Posters. 2.

https://ir.lib.uwo.ca/psychd_posters/2 


\section{Ideal Mate Preferences and Relationship Initiation}

Kristi Chin

Honors B.Sc. in Psychology

Department of Psychology, Western University, Canada

Thesis Advisors: Lorne Campbell, Ph.D. and Sarah Stanton, M.Sc

ABSTRACI

The present study investigates the extent to which individuals initiate romantic relationships with others who more closely match their ideal mate preferences. To test this question, 433 single participants' ideal mate preferences and perceptions of themselves on across three categories of traits were measured via online surveys over a six-month period. If participants became involved in a romantic relationship during the six months, they were asked to provide the contact information for their partners. If the partners agreed to join the study, they were asked to provide self-evaluations on the same three categories of traits. Comparisons between the original participant's ideal mate preferences and their partner's self-perceptions will be analyzed. This will determine whether individuals initiate relationship with others who have greater consistency with their ideals and their partner's self-perceptions.

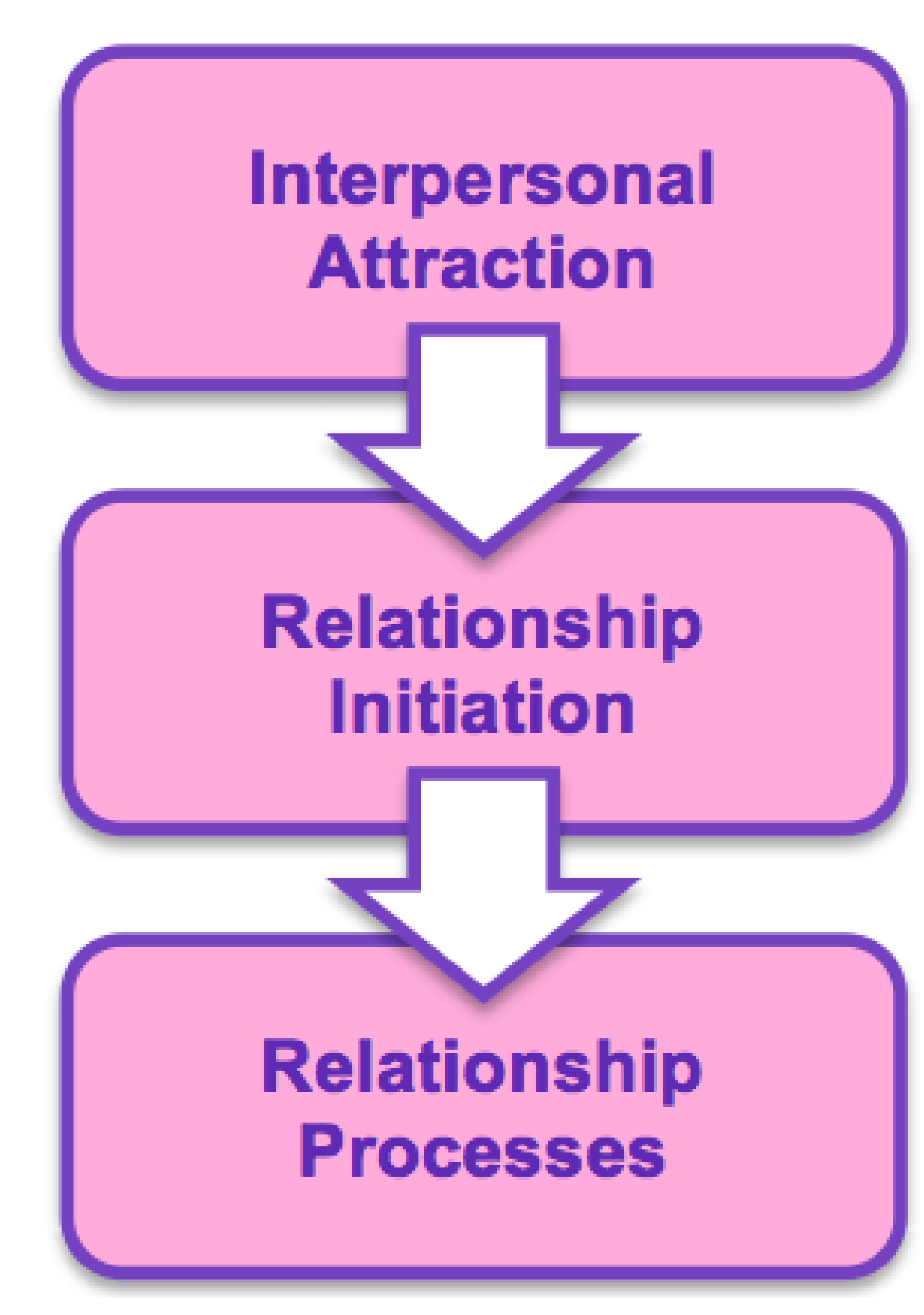

INTRODUCTION

Ideals: mental constructs that represent an idea of traits we are attracted to in potential partners (Fletcher et al., 1999)

- Relationship initiation: The transition from being single to in a relationship.

- Research question: Do individuals initiate relationships with those that more closely match their ideals?

Supporting literature: Men of higher social status have more dating partners and the number of dating partners women have decreases linearly with age (Pérusse, 1994)

- Conflicting literature: Reported ideals at speed dating did not meaningfully predict initiation (Eastwick and Hypothesis: initiation.

Purpose: To understand the qualities individuals desire in partners, and how these influence selecting partners and the understudied stage of initiating relationships.

\section{MIETHOD}

\section{Participants:}

433 participants (186 males, 242 females) ranged from 14 and 80 years $M=24.32, S D=8.91)$

- 38 partners (22 males, 15 females) ranged from 19 and 50 years $(M=$ 24.09, $S D=1.10)$.

\section{Measures:}

- Self and partner standards scale: Ideal importance and self-perceptions measured with 38 attributes from prior research (Fletcher, Simpson, Thomas, \& Giles,

999)

- Global self-evaluation: 10-item Rosenberg self-esteem Scale (Rosenberg 1965) measures general feelings of self-worth.

Procedure:

-Participants emailed surveys every month over 6 month period

- If participants became involved in relationship they were emailed the

Relationship survey and asked to provide partner's email address. New

partners emailed the Partner Relationship survey.

-Participants in relationship and partners received 3 month follow-up.

\section{FIIDRARCHIICAL LINDAR MIODELING}

HLM is appropriate for analyzing data that has a nested data structure: In this study, couple represents upper level and each partner represents lower level.

- HLM analysis will generate an intercept and slope for each couple Intercept: Average self-perception score when statistically controlling for other partner's ideal preferences.

Slope: Regression coefficient of the association between ideal preferences of one partner and self-perceptions of the other partne

- Intercepts and slopes for each couple are averaged

Average intercept: average self-perceptions across the sample when controlling for the other partner's ideal preferences)

Average slope: average association between ideal preferences and partner self-perceptions across the sample).

\section{Tests of Hypotheses}

- Model 1: Self-perceptions of new partner are outcome, idea preferences of original partner are predictor

- Model 2: Self-perceptions of original participant are outcome, ideal preferences of new partner are predictor

\begin{tabular}{|c|c|c|c|c|}
\hline \multicolumn{5}{|l|}{ Results } \\
\hline \multicolumn{5}{|c|}{ Models of Primary Hypothesis and Discriminant Analyses } \\
\hline \multirow[t]{2}{*}{ Predictor } & \multicolumn{2}{|c|}{$\begin{array}{l}\text { Participant's } \\
\text { Ideals }\end{array}$} & \multicolumn{2}{|c|}{$\begin{array}{l}\text { Partner's } \\
\text { Ideals }\end{array}$} \\
\hline & $b$ & SE & $b$ & SE \\
\hline Original Analysis & & & & \\
\hline Participant's Self-Perceptions & - & - & $.33^{* * *}$ & .06 \\
\hline Partner's Self-Perceptions & $.36^{* * *}$ & .07 & - & - \\
\hline \multicolumn{5}{|l|}{ Global Self-Evaluation Control } \\
\hline Participant's Self-Perceptions & - & - & $.25^{\star \star \star}$ & .05 \\
\hline Partner's Self-Perceptions & $.27^{* \star *}$ & .06 & - & - \\
\hline \multicolumn{5}{|l|}{ Self-Perception Control } \\
\hline Participant's Self-Perceptions & - & - & $.17^{\star \star \star}$ & .03 \\
\hline Partner's Self-Perceptions & $.42^{\star \star \star}$ & .05 & - & - \\
\hline \multicolumn{5}{|l|}{ Dating Partner Prior Control } \\
\hline Participant's Self-Perceptions & 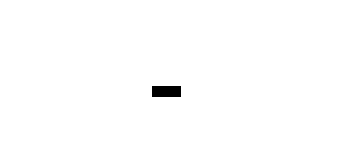 & & $.37^{\star \star \star}$ & .07 \\
\hline Partner's Self-Perceptions & $.42^{\star \star \star}$ & .08 & - & - \\
\hline Note. ${ }^{* * *} p<.001$ & & & & \\
\hline
\end{tabular}

\section{DISCUSSION}

- Results revealed that individuals initiate relationships with those that more closely match their ideal mate preferences.

- To date, there has been no research on ideals and relationship initiation.

- Implications:

- Increases understanding of the degree ideals influence who we select as partners and who we initiate relationships with

- First study to analyze relationship initiation over long period of time, informing the debate on impact of ideals on this stage of relationships.

\section{LIMITIATIONS}

Majority of participants were university students

Many reluctant to give partner's email address

- Research did not control for whether individuals were looking for short- or long-term relationship

\section{FUTURE DIRECTIONS}

- Compare age and maturity

- Analyze cross cultural differences

- Follow-up to compare associations at relationship initiation to associations at serious dating and/or marriage 